\section{It's back and bigger than ever!}

Technology is constantly evolving and chances are it will have been a few years since you invested in new equipment for the practice. Your existing tools might be working just fine, and may not ever become obsolete, but aren't you just a little bit intrigued to find out just what's out there and how it might assist you in your day-to-day work? At this year's Dental Showcase, which takes place from 19-21 October 2017 at Birmingham NEC, you really will gain an insight into the latest innovation in the industry.

To use a common analogy, if you've looked after your iPhone 4 it will still be perfectly functional and you may be perfectly happy with it, but what if you had an iPhone 7 in your hand and could see the advanced camera, hear the improved audio, feel the streamlined shape and learn about the better battery life, not to mention the fact that it was water resistant? Well, at Dental Showcase you have the opportunity to see, hear, feel and learn about all that's new in dentistry. Moreover, as everything is under one roof you can comfortably do it all in a day, and earn yourself some valuable CPD in the process.

\section{An impressive material for a wide range of indications}

With a high level of hydrophilicity, Impregum Penta polyether impression material from $3 \mathrm{M}$ Oral Care will allow you to reproduce highly-detailed, void-free impressions every time.

This impressive material can be applied to a wide range of indications, including crown and bridge, inlay and onlay, functional and implant impressions.

What's more, thanks to its unique 'snap-set' behaviour, Impregum impression material will not start setting until the working time ends, allowing you ample time to achieve the most accurate impression.

To discover how you can improve your dental impressions, contact the $3 \mathrm{M}$ Oral Care team today to discuss Impregum Penta impression material.

Call 08456025094 or visit www.3Mespe.co.uk

$3 \mathrm{M}$, Impregum and Penta are trademarks of the $3 \mathrm{M}$ Company.

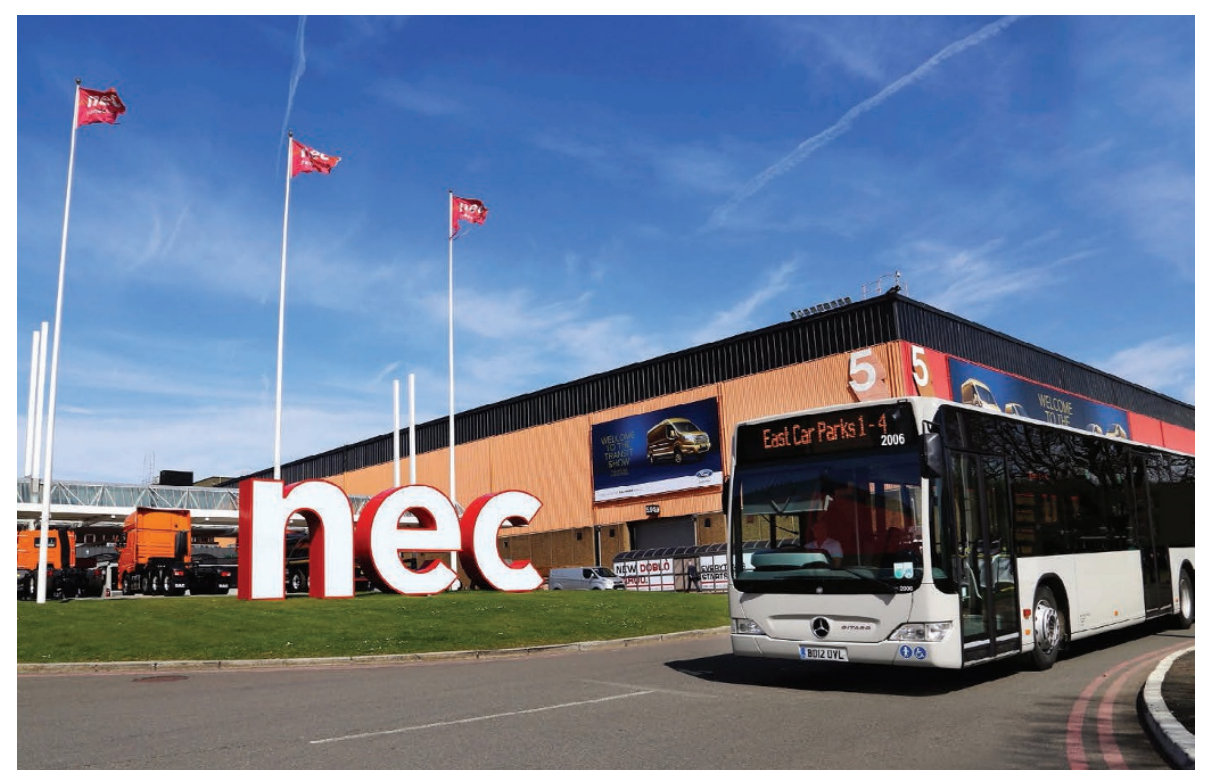

New to this year's Dental Showcase will be the Dental Surgery of The Future. Purpose built for the show it will include a reception area, built to the highest specification, a patient information zone and a fully functioning surgery, equipped with only the very latest technology. The futuristic surgery will have seating, so that delegates can relax during keynote speeches and demonstrations. As well as learning about what's new in the industry, you will also be able to listen to talks on topics such as handling medical emergencies, $3 \mathrm{D}$ printing, business management matters and IRMER guidelines. Delegates will also have the opportunity to play with all the new gadgets and gizmos in the surgery.

To register your place at Dental Showcase visit http://www.dentalshowcase.com/.

\title{
Are you seeking high performing but affordable dental implants?
}

Dentists in Great Britain seeking high performing but affordable dental implants can now partner with Anthogyr Limited to make implant treatment more accessible to patients. The company offers a comprehensive range of implants, prosthetics and CAD/ CAM to support practice growth.

Anthogyr Limited is led by General Manager, Chris Meldrum (pictured, right), supported by National Key Accounts Manager, Chris Bartlett (left). Between them, they benefit from more than six decades'

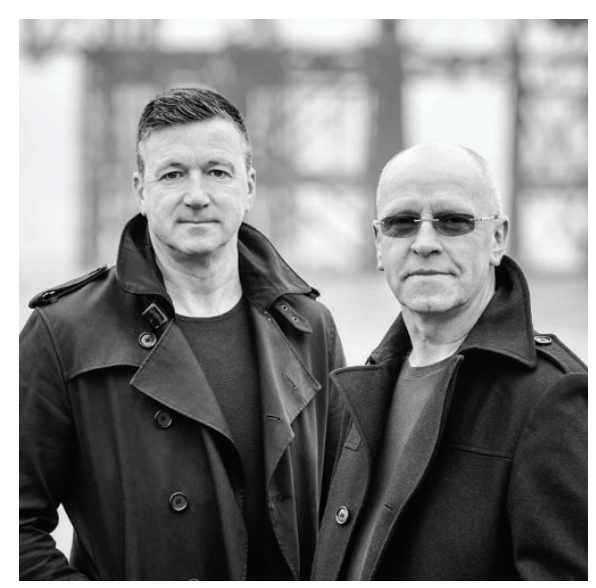

experience in the UK dental industry, and more than a quarter of a century specifically in implant dentistry. The parent company, Anthogyr SAS, was established 70 years ago. This independent, family-run business designs, manufactures and distributes a complete range of products to support dentists in treating millions of patients across the world.

The Axiom range provides dentists with implants suitable for every clinical indication. The system benefits from a conical connection and platform-switching for more predictable and aesthetic outcomes. Meanwhile, Simeda CAD/CAM offers a flexible, customised digital service which is becoming the software of choice for dental technicians globally. Complemented by easy-to-use and time-saving surgical and prosthetics kits and a comprehensive range of components and instruments, Anthogyr Limited has everything needed to grow your implant business.

Contact Chris Meldrum today to book your test drive on freephone 08000857119 or byemail info.uk@anthogyr.com. 